should be out of bed by the fifth day. He should drink large quantities of water from the onset.

10. Anesthetic is sub judice. Phosphate of sodium should be administeerd to keep the urine acid; and urotropin as an antiseptic. The personal equation must never be lost sight of in operating these cases, and attention to every small detail of the patient's general condition is necessary for the best results.

[I am indebted to Dr. E. F. Brandt, interne of Mercy Hospital, for the excellent photographs.]

BIBLIOGRAPHY.

1. E. A. Schaefer, Text-Book of Physiology, 1900.

2. Medical Record, Dec. 1, 1901.

3. Lancet, 1901

1. Am. Text-Book of Physiology, 1896.

5. Med. Rec., March 9, 1901.

6. Wishard, N. Y. Med. Journal, Aug. 17, 1901

7. Med. Rec., Dec. 21, 1901.

8. Med. Rec., March 23, 1901 ..

9. Medical News, June 15,1901

10. Medical Rerord, Dec. 28, 1901 .

11. Medical $R \in$ zord, Nov. 30, 1901

12. Medical Record, Aug. 3, 1901.

13. Med. Rec., March 2, 1901.

14. JOURNAI A. M. Nov, 2, 1901.

15. La Presse Medicale, Oct. 16, 1901 .

16. Brit. Med. Journal, July 2, 1901.

17. Medical Record, Nov. 24, 1901

18. London Lancet. Nov. $9,1901$.

19. Med. Rec., July 6, 1901.

20. Yed Rec, Nov, 2, 1901.

21. Med. Rec., Nov. 9, 1901.

22. Med. News, Nov. 2, 1901.

23. Med. Rec., May 18, 1901 .

24. I'hil. Med. Jour., Nov. 2, 1901.

\section{CASE OF TYPHOID FEVER}

COMPLICATED BY A THROMBO-PHLEBITIS OF THE LONG SAPHENOUS VEIN, A SEVERE HEMORRHAGE FROM TIE BOWEL, INFECTION OF THE CLOT, WITH RECOVERY.

GEO. C. ARMSTRONG, M.D. CAMBRIDGE, NEB.

A young man, aged 20, of spare build, was seen in the writer's office Aug. 21, 1901. He complained of severe frontal headache, dizziness, ringing in the ears, pains in the eyes, loss of appetite, gurgling in the abdomen, backache, diarrhea, exhaustion and nose-bleed. The tongue was thickly coated, spleen and liver enlarged, gurgling and tenderness in the right iliac fossa, and some cough. Pulse was 72 , temperature 102.5 .

The patient was given a laxative, sent home to bed, and a sample of urine was ordered for examination. The following day he was seen at his home; temperature was 104, pulse 82 in the evening; urine showed the diazo-reaction of Ehrlich and a diagnosis of typhoid fever was made. Systematic cold sponging was practiced every three hours, a milk and beef juice diet was ordered, at the same time an intestinal antiseptic was continually given. At no time during the treatment was the temperature above 103 , pulse ranging between 75 and 85. At the end of the fourth week the appetite became better and some diarrhea which was present all through the sickness, ceased, and convalescence became apparently established. Stimulants in the form of whisky and strychnia were given the patient as there was an altered first heart tone and a systolic murmur heard at the apex.

On September 17 the patient complained of pain in the left calf, which extended upwards along the inner surface of the thigh into the groin. The left testicle was also painful. The upper thigh was some swollen, and the long saphenous vein could be distinctly palpated from a little above the ankle to the middle of the thigh. 'There was no swelling of the limb below the knee. The spermatic vein presented the same condition as that of the $\operatorname{limb}$; the testicle was not apparently affected. Coincidently with the formation of the thrombus, the temperature arose to 105.2 , pulse 116 .

The limb was enveloped in cotton and a roller bandage applied, and the testicle was supported. Four days after the onset of the phlebitis the temperature was 100.5 , pulse 90 ; some pain existed in upper limb and along the spermatic vein.

In the afternoon of the same day he felt a fulness in the abdomen, saw various colors. was nauseated, sleepy and thirsty, was short of breath and desired to evacuate his bowels. He immediately passed into the bedpan, with much force, two liters of dark blood.

The hips were elevated, morphin and ergotin given hypodermically: ice to the abdomen and perfect quiet ordered. His condition was now one of acute anemia and normal salt solution was injected, a new rubber fountain syringe and an ordinary aspirating needle, which was sterilized by boiling in soda solution, being used. One liter was given under the skin on each side. the needle being inserted a little above and external to the nipple. The effects of the salt solution was quickly noticed, and in six hours the patient passed a full 16 ounces of urine and felt much better. The bowels moved spontaneously the third day after the hemorrhage. The temperature and pulse gradually fell, when one week from the day of his hemorrhage he had a pronounced chill, lasting 40 minutes; temperature 105.5, pulse 135. Profuse perspiration followed. The pain in the limb which had by this time nearly ceased, now became much worse, and varied in severity according as the temperature arose or fell, being worse as the temperature went up.

One week from the day of his first chill, a second came on, lasting as long and was as severe as the first, followed by the most exhaustive sweats; temperature and pulse arose as high as before. The temperature and pulse oscillated as before for ten days, when he had a third chill lasting not quite so long as the first two; sweats again'followed. After each chill with rise of temperature the skin presented all over the trunk. especially on the lower abdomen and back, a fine pinhead pustular eruption, which gave the patient much annoyance on account of the itching and smarting. Frequent turning of the patient with bathing and rubbing with alcohol to prevent decubitus was practiced.

Iron, quinin and strychnia were given to help correct the anemia as well as a tonic and stimulant, with a liberal allowance of predigested milk, ice cream and broths, and finally the patient began rapidly to improve; the appetite returned, the temperature and pulse oscillating for one week, and finally became normal and frequently subnormal, when in nine weeks from his initial visit to the office, the patient was sitting up most of the time. He now feels entirely well, having worn a bandage for five weeks after beginning to walk, to help counteract the swelling. The distressing intestinal catarrh, from which he suffered previous to his sickness and which resisted all lines of treatment, is now entirely cured.

The case is interesting from the facts that an apparently moderate attack of typhoid fever is no criterion from which to deduce a prognosis; this case demonstrated beyond a reasonable doubt the value of the salt solution that was used to correct the acute anemia. 